Provided for non-commercial research and education use. Not for reproduction, distribution or commercial use.

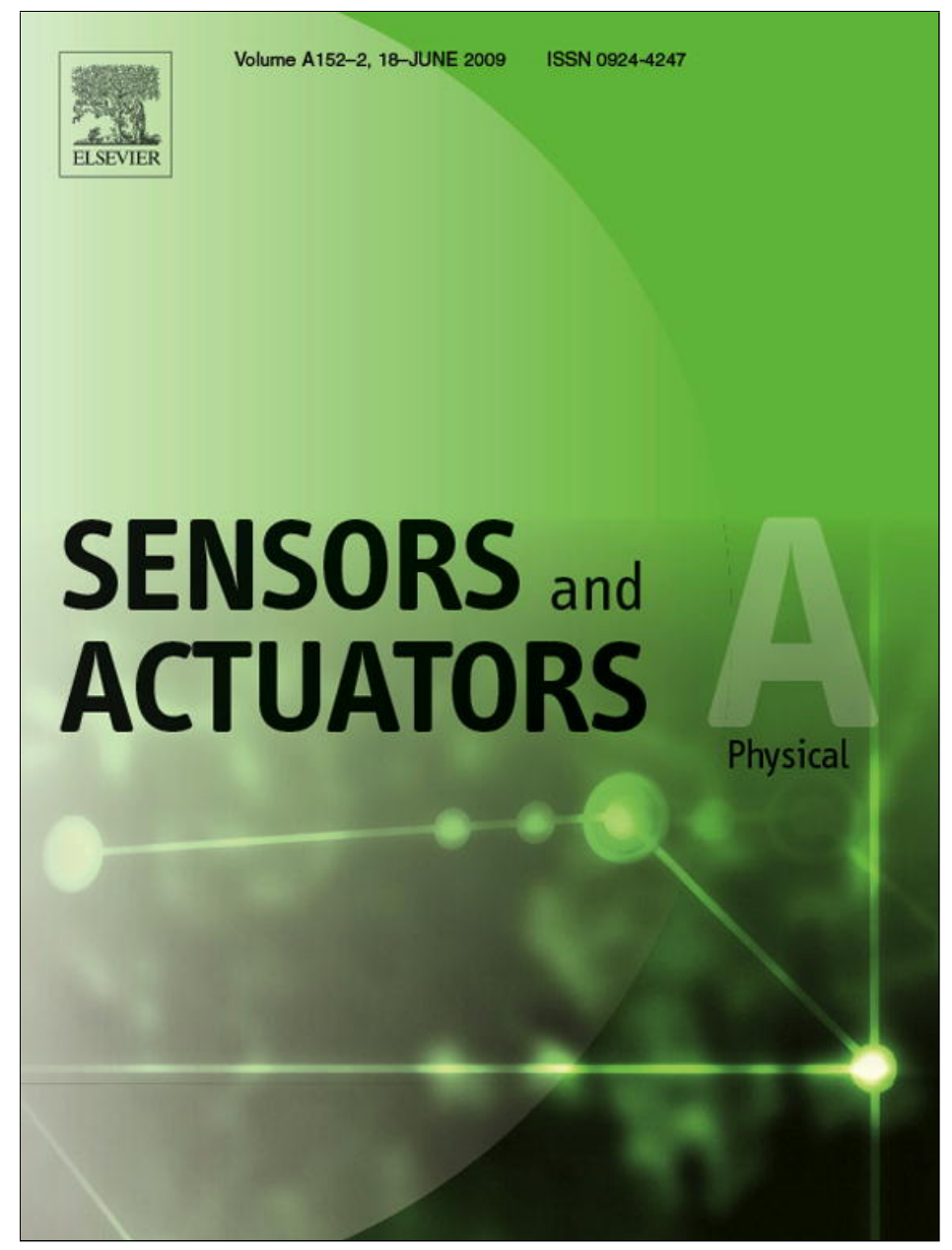

This article appeared in a journal published by Elsevier. The attached copy is furnished to the author for internal non-commercial research and education use, including for instruction at the authors institution and sharing with colleagues.

Other uses, including reproduction and distribution, or selling or licensing copies, or posting to personal, institutional or third party websites are prohibited.

In most cases authors are permitted to post their version of the article (e.g. in Word or Tex form) to their personal website or institutional repository. Authors requiring further information regarding Elsevier's archiving and manuscript policies are encouraged to visit:

http://www.elsevier.com/copyright 


\title{
Development of a hybrid ferrofluid seal technology for miniature pneumatic and hydraulic actuators
}

\author{
M. De Volder*, D. Reynaerts \\ Dept. of Mech. Eng., Div. PMA, Katholieke Universiteit Leuven, Celestijnenlaan 300B, 3001 Leuven, Belgium
}

\section{A R T I C L E I N F O}

\section{Article history:}

Received 24 November 2008

Received in revised form 12 January 2009

Accepted 9 April 2009

Available online 24 April 2009

\section{Keywords:}

Ferrofluid

Microseal

Fluidic microactuator

Microrobotics

\begin{abstract}
A B S T R A C T
Future microrobotic applications require actuators that can generate a high actuation force and stroke in a limited volume. Up to now, little research has been performed on the development of pneumatic and hydraulic microactuators, although they offer great prospects in achieving high force densities. One of the main technological barriers in the development of these actuators is the fabrication of powerful seals with low leakage. This paper presents a seal technology for linear fluidic microactuators based on ferrofluids. A design and simulation method for these seals has been developed and validated by measurements on miniaturized actuator prototypes. These actuators have an outside diameter of $2 \mathrm{~mm}$, a length of $13 \mathrm{~mm}$ and have been tested using both pressurized air and water. Our current actuator prototypes are able to operate at pressures up to $1.6 \mathrm{MPa}$ without leakage. At these pressures, forces up to $0.65 \mathrm{~N}$ have been achieved. The stroke of the actuators is $10 \mathrm{~mm}$.
\end{abstract}

(c) 2009 Elsevier B.V. All rights reserved.

\section{Introduction}

In order to improve the force density of microactuators, this research focuses on the development of actuators driven by pressurized gasses or liquids. Despite reports on the high force and power densities of these actuators [1-7], they remain uncommon in microsystems. In the past, a number of promising inflatable hydraulic balloon actuators have been reported [8-10], nevertheless these actuators are limited to short actuation strokes and have a non-linear actuation behaviour. In large scale applications, pistoncylinder pneumatic actuators are used because they can achieve relatively large strokes and their actuation force is a linear function of the applied pressure. Nevertheless, appropriate seal technologies need to be developed in order to apply these actuators in microsystems. Classic seal technologies such as rubber O-rings are unsuitable at microscale since small shape or size variations of the rubber O-ring, the seal house or the piston result in either high friction or leakage. In order to avoid these strict production requirements, this paper proposes to employ liquid seals based on a ferrofluid. The implementation of these seals is comparable to that of rubber O-rings, but the seal ring consists of a liquid (in this case a ferrofluid) instead of a rubber. Ferrofluids are a stable colloidal suspension of single domain superparamagnetic particles in a carrier fluid [11,12]. When a magnetic field is applied on a ferrofluid, it moves to the location with the highest magnetic flux density.

\footnotetext{
* Corresponding author.

E-mail address: michael.devolder@mech.kuleuven.be (M. De Volder).
}

This property allows to confine the ferrofluid in for instance a ring shape, and hence to create a seal. The liquid nature of these seal rings allows them to adjust their shape to production errors on the piston and the seal house. This adaptation in shape does not affect the leakage or friction of the seals. Moreover, promising properties such as the restoration of the seal after a pressure overload have been observed.

Similar ferrofluid seals have already been proposed for rotating shafts [13-15]. This paper differs from former publications because it describes linear seals and because it focuses on the miniaturisation of these seals. Regarding miniaturisation, it is interesting to note that the particles suspended in ferrofluids are typically only $10 \mathrm{~nm}$ in diameter. This makes these fluids more attractive for microsystems than for instance magnetorheologic fluids [16]. In addition, a new hybrid seal configuration that can resist high pressures without leakage is developed and tested.

Fig. 1 depicts the actuator configuration that is investigated in this paper. It is a typical hydraulic double acting actuator, which means that the actuator is able to generate both pushing and pulling forces depending whether the pressure is applied to the pressure port 1 or 2 , respectively (see Fig. 1 ). The goal of this research is to develop an actuator with a section of $1 \mathrm{~mm}^{2}$ and a length of $15 \mathrm{~mm}$ that can generate forces of $1 \mathrm{~N}$ and a stroke of $10 \mathrm{~mm}$. These specifications are based on requirements for a tool for minimally invasive surgery. However, these actuators can also find applications in a large number of other microrobotic applications such as inspection and assembly robots or tactile displays. 


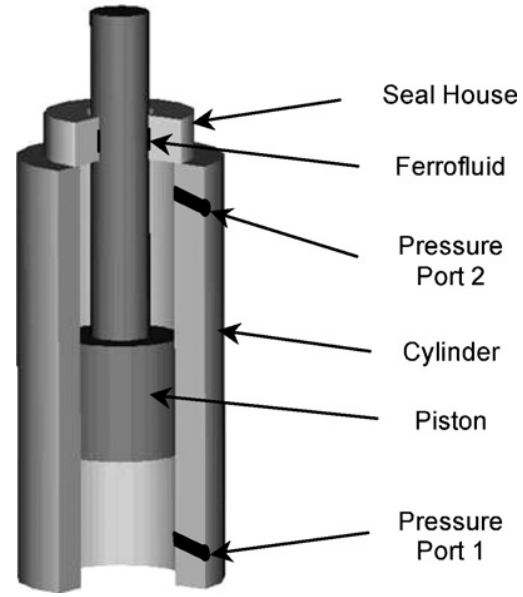

Fig. 1. General layout of the fluidic actuators investigated in this paper.

\section{Actuator design}

\subsection{Ferrofluid seals}

As pointed out by Rosensweig [11], the classic Bernoulli equation can be extended to Eq. (1) in order to describe ferrofluids:

$\rho\left(\frac{\partial v}{\partial t}+v \cdot \nabla v\right)=-\nabla p+\mu_{0} M \nabla H+\eta \nabla^{2} v+\rho v$

with $v$ the flow velocity, $t$ the time, $p$ the composite pressure, $\mu_{0}$ the permittivity of free space, $H$ the magnetic field, $\rho$ the density of the fluid, $g$ the gravity constant and $M$ the magnetization (magnetic dipole moment per volume). From Eq. (1), it can be derived that the maximum seal pressure of a ferrofluid seal is ruled by Eq. (2) [11]:

$\Delta P=M_{S} \cdot N \cdot\left(B_{\max }-B_{\min }\right)$

with $M_{S}$ the saturation magnetization, $N$ the number of seal stages and $B_{\max }$ and $B_{\min }$ the maximal and minimal value of the magnetic flux density in the ferrofluid, respectively. Eq. (2) shows that the maximum seal pressure can be increased by optimizing following parameters:

- First, the material constant $M_{s}$ should be as high as possible. In this research we investigated a ferrofluid from Ferrotec Corp. [12]. Measurements reported in an earlier publication [3] show that the saturation magnetization is probably around $40 \mathrm{kA} / \mathrm{m}$.

- Second, the number of seals $N$ that are placed after each other should be as high as possible. Nevertheless, $N$ is limited because a high number of seals result in complicated structures. In addition, for a same seal length, a high $N$ value results in higher values for $B_{\min }$ which reduces the gain in seal pressure per seal step (see Eq. (2)). Therefore, this paper only investigates single stage $(N=1)$ and double stage $(N=2)$ seals.

- The last design parameter that should be maximized is $\left(B_{\max }-B_{\min }\right)$. This parameter is optimized using finite element simulations of the magnetic flux density for different seal geometries.

A study of different seal designs based on other arrangements of the permanent magnets within the seal has been discussed in an earlier publication [3]. This study showed that permanent magnets with a radial magnetization allow to generate higher seal pressure than magnets with an axial magnetization. Figs. 2 and 3 show simulations of the magnetic flux density along the piston wall (see dashed line) for magnets with a radial magnetization. Fig. 2 illustrates single stage seals while double stage seals are sketched in

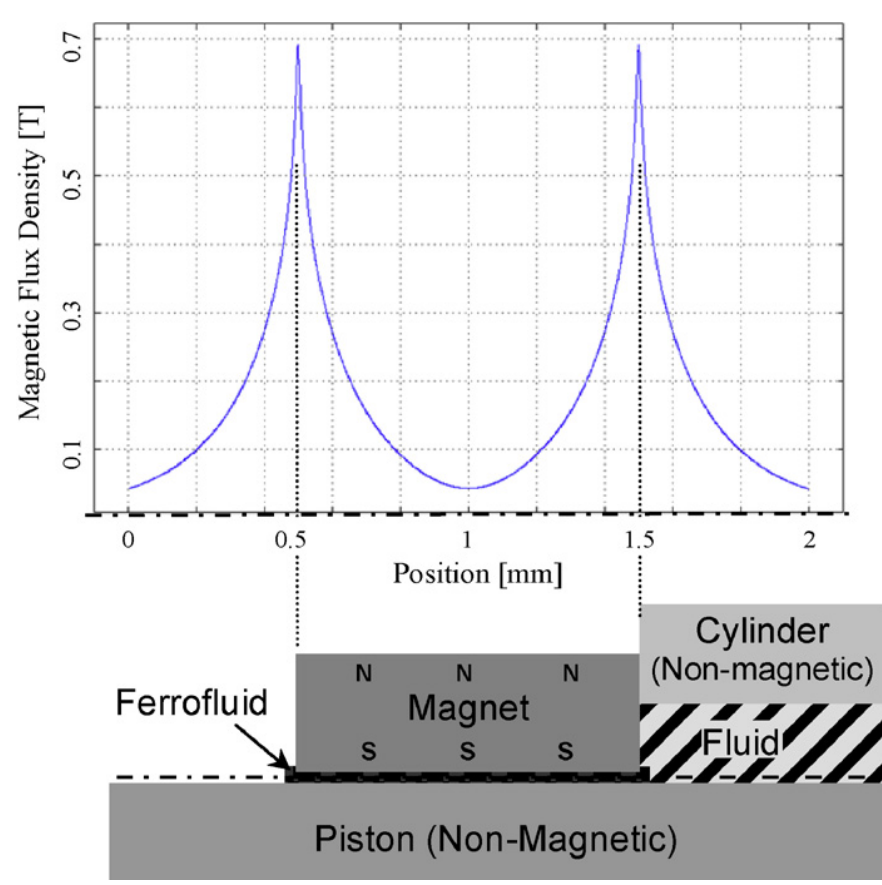

Fig. 2. Top: Magnetic flux density as a function of the position in a single stage ferrofluid seal. Bottom: Sketch of a seal cross-section. The dashed line indicates the location where the magnetic flux is calculated.

Fig. 3. From the latter figure and Eq. (2), it can be derived that the maximum seal pressure of a double stage seal is approximately $112 \mathrm{kPa}\left(2^{*} 40 \mathrm{kA} / \mathrm{m}^{*}(1.6 \mathrm{~T}-0.2 \mathrm{~T})\right)$. The magnets used in these simulations all have an inside diameter of $0.3 \mathrm{~mm}$, an outside diameter

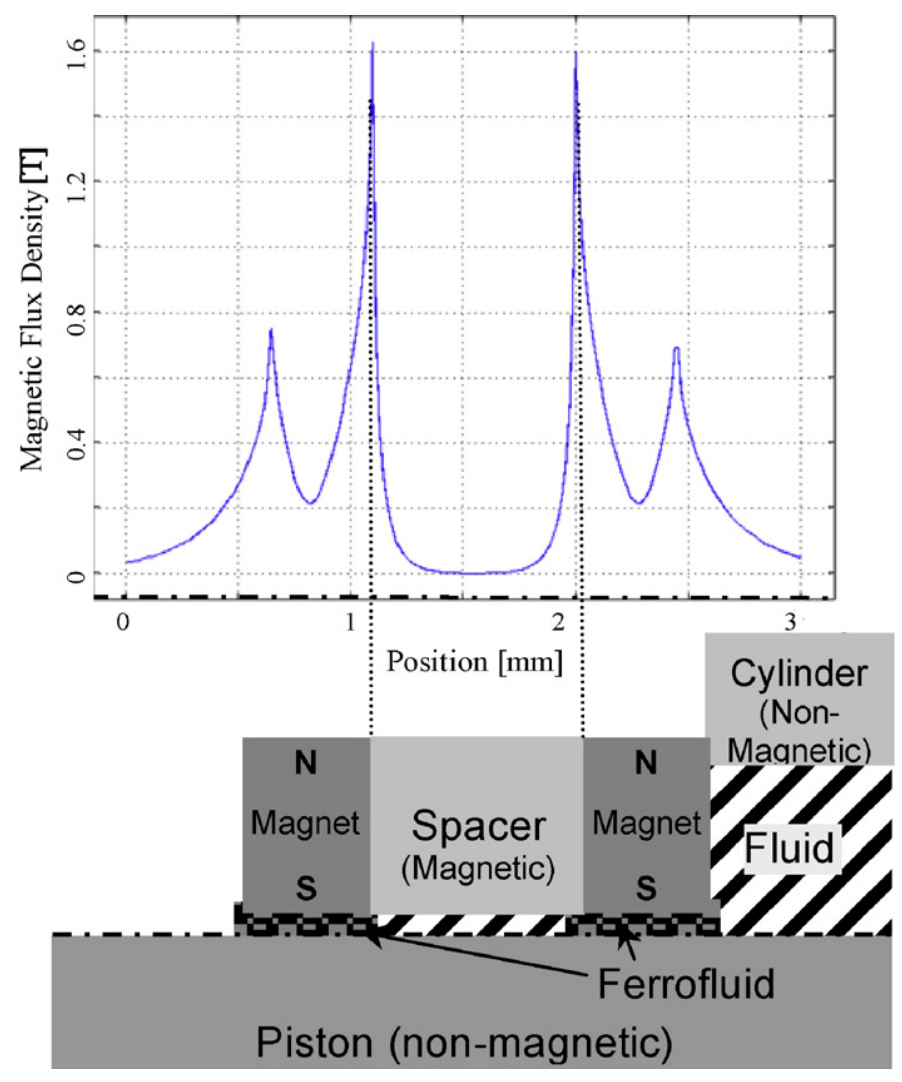

Fig. 3. Top: Magnetic flux density as a function of the position in a double stage ferrofluid seal. Bottom: Sketch of the cross-section of the seal. The dashed line indicates where the magnetic flux is calculated. 


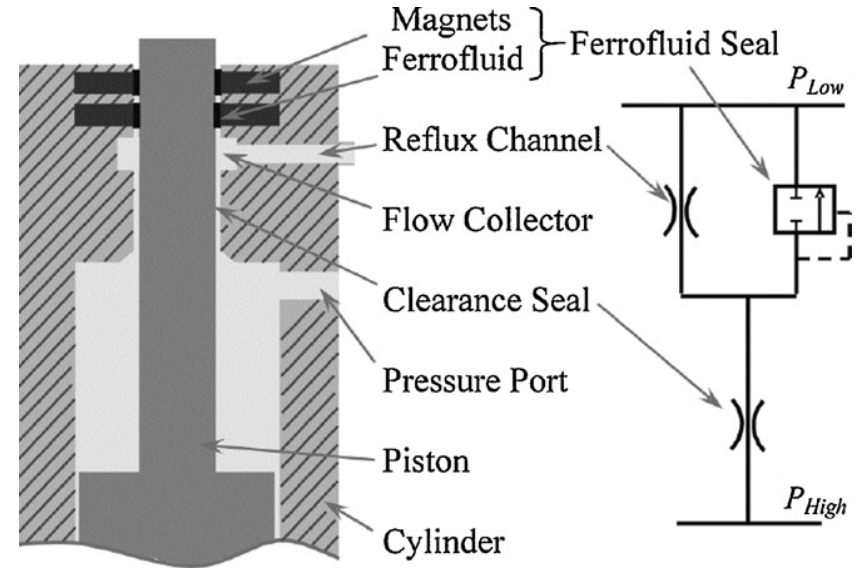

Fig. 4. Schematic cross-section of a hybrid ferrofluid seal (left) and an equivalent hydraulic scheme of the seal (right).

of $1.2 \mathrm{~mm}$ and a remanent field $B_{r}$ of $800 \mathrm{mT}$. The clearance between the seal and the piston is maximally $5 \mu \mathrm{m}$, and the spacer is made out of magnetically conductive steel.

\subsection{Hybrid seals}

As pointed out in the introduction of this paper, the aim of this research is to achieve actuation forces in the range of $1 \mathrm{~N}$. If a $1 \mathrm{~mm}^{2}$ piston is used, this means that pressures of typically $1 \mathrm{MPa}$ need to be sealed. However, the above discussion shows that the maximum seal pressure of the ferrofluid seals investigated in this paper is limited to approximately $100 \mathrm{kPa}$. Therefore, a novel hybrid seal technology that combines a clearance seal [1] with the ferrofluid seals described above has been developed. The operation principle of these seals is illustrated in Fig. 4. In the case of hybrid ferrofluid seals, the pressure load that is applied on the seal is forced through a small clearance before it reaches the ferrofluid seal. While the driving fluid is flowing through the clearance, part of the pressure load is dissipated, and therefore the pressure that must be overcome by the ferrofluid seal is reduced. In order to dissipate part of the pressure load, a certain amount of flow through the clearance seal is necessary. This flow is gathered in the collector and channeled back through the reflux channel to the fluid reservoir (see Fig. 4). The flow collector ensures an even pressure distribution over the circumference of the seal. The right hand side of Fig. 4 shows a hydraulic scheme of the hybrid seal. In this figure, the ferrofluid seal is represented as an overpressure valve (i.e. a valve that opens at the maximum seal pressure of the ferrofluid seal), the reflux channel and the clearance seal are represented by flow restrictions. As can be seen in this scheme, the clearance seal and the reflux channel are a hydraulic equivalent of an electric voltage divider. This analogy allows to dimension the seal such that the pressure acting on the ferrofluid seal stays below its threshold value. If the flow resistance of the clearance seal $\Re_{\text {Clearance }}$ is large in comparison with the flow resistance of the reflux channel $\Re_{\text {Channel }}$, the pressure $P$ working on the ferrofluid seal can be reduced considerably. This gain in seal pressure $G$ can be estimated by Eq. (3) in the case of laminar flow:

$G=\frac{\Re_{\text {Channel }}+\Re_{\text {Clearance }}}{\Re_{\text {Channel }}}$

with

$$
\begin{aligned}
1 / \Re_{\text {Clearance }}= & \frac{\pi \cdot R_{o}^{4}}{8 \cdot \eta \cdot l}\left(1-k^{2}\right) \cdot\left[1+k^{2}-\frac{1-k^{2}}{\ln (1 / k)}\right] \\
& +\frac{\pi \cdot R_{o}^{2} \cdot U}{P}\left(\frac{1-k^{2}}{2 \cdot \ln (1 / k)}-k^{2}\right) \\
1 / \Re_{\text {Channel }}= & \frac{\pi \cdot R_{\text {Tube }}^{4}}{8 \cdot \eta \cdot l_{\text {Tube }}} \text { and } k=\frac{R_{o}}{R_{i}}
\end{aligned}
$$

$R_{i}$ is the diameter of the piston rod, $R_{o}$ is the diameter of the clearance seal, $R_{\text {Tube }}$ is the diameter of the reflux channel, $l$ is the length of the clearance seal, $l_{\text {Tube }}$ is the length of the reflux tube, $\eta$ is the viscosity of the driving fluid and $U$ is the relative speed of the piston. Furthermore, the flow $Q$ can be kept very low if the flow resistance of the clearance or the reflux channel is high enough. The flow rate can be estimated based on Eq. (4), in which $\Delta P$ is the total pressure drop over the clearance seal and the reflux channel:

$$
Q=\frac{\Delta P}{\Re_{\text {Channel }}+\Re_{\text {Clearance }}}
$$

Hybrid seals are particularly interesting for microdevices since they consist of relatively simple structures and allow to seal high pressures with relatively low friction forces. In addition, ferrofluid seals are relatively insensitive to production errors. In what follows we will investigate a seal with following dimensions: $R_{\text {Tube }} 0.14 \mathrm{~mm}$, $l_{\text {Tube }} 100 \mathrm{~mm}, R_{i} 0.15 \mathrm{~mm}, R_{o} 0.158 \mathrm{~mm}, l 0.7 \mathrm{~mm}, \eta 0.001$ Pa s and $U=0 \mathrm{~m} / \mathrm{s}$. In this case, $G=11.1$ and $Q=13.6 \mu \mathrm{l} / \mathrm{s}$ at a pressure of $100 \mathrm{kPa}$. However, it should be noted that if the piston is placed completely eccentric in the seal orifice, the flow resistance $\Re_{\text {Clearance }}$ decreases with a factor 2.5 [1]. In that case $G=5$ and $Q=30 \mu \mathrm{l} / \mathrm{s}$ at a pressure of $100 \mathrm{kPa}$. This numerical example clearly shows that

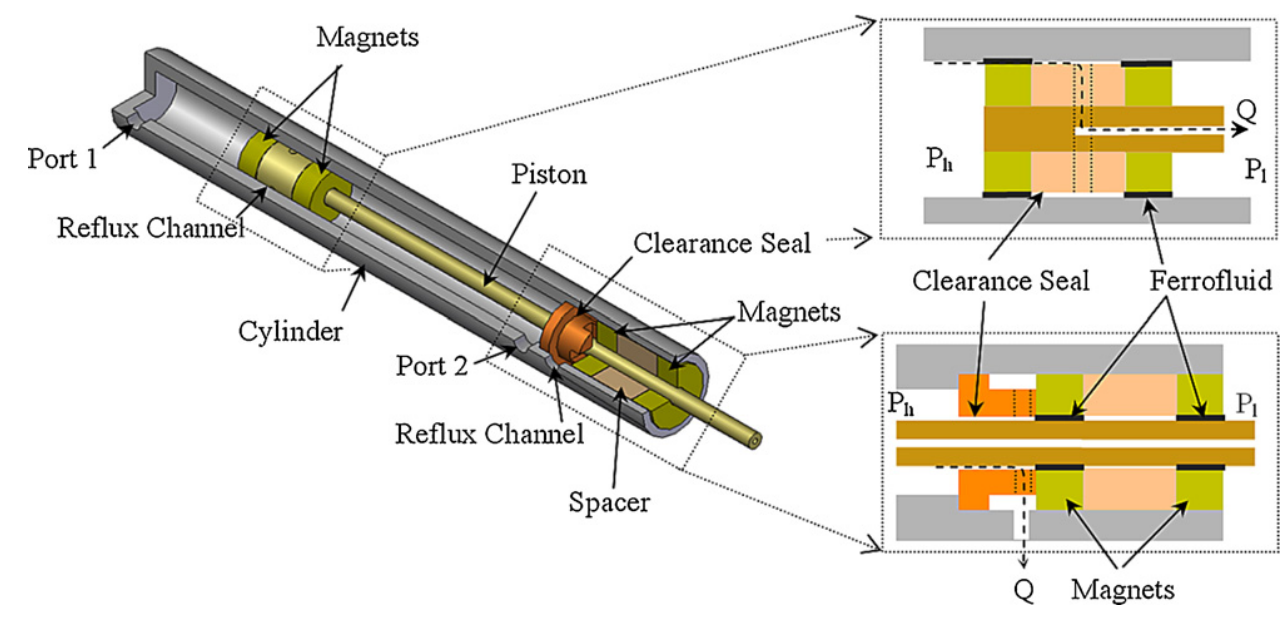

Fig. 5. Illustration of a practical implementation of an actuator with two hybrid ferrofluid seals. 


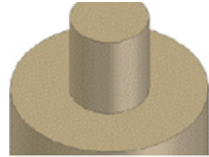

1. Precision Turning

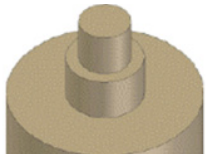

2. $\mu \mathrm{EDM}$ Milling

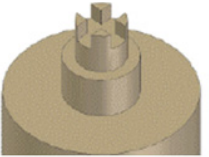

3. $\mu \mathrm{EDM}$ Milling

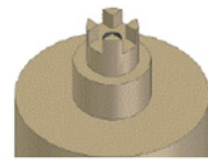

4. $\mu \mathrm{EDM}$ Drilling

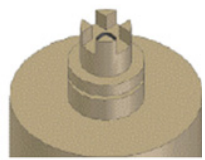

5. Wire $\mu \mathrm{EDM}$

Fig. 6. Fabrication process of the pressure divider.

most of the pressure load is supported by the clearance seal. The ferrofluid seal is however still necessary in order to avoid any leakage of fluid outside the cylinder.

Fig. 5 sketches a practical implementation of the actuator shown in Fig. 4. As illustrated in this figure, it is also possible to implement a hybrid ferrofluid seal on the piston of the actuator. Many different seal configurations can be designed for this purpose, the seal shown in Fig. 5 works as follows: when the driving pressure $P_{h}$ (Fig. 5, right) reaches a certain threshold value, the ferrofluid seal around the magnet on the left hand side will fail and allow a certain leakage $Q$ to flow past the magnet into the reflux channel inside the piston. In this case, the magnet on the left hand side is acting as a restriction that reduces the pressure acting on the ferrofluid seal on the right hand side. Unless the actuator is driven by pressurized air, a tube needs to be connected to the end of the piston in order collect the fluid that is flowing through the clearance seal. Since a small leakage between both pressure chambers is less detrimental than a leakage to the outside world, it is usually sufficient to use a clearance seal between the pressure chambers as illustrated in Figs. 1 and 4 .

\section{Actuator fabrication process}

In what follows, the production of each of the components shown in this Fig. 5 will be discussed. The fabrication of the pressure divider is illustrated in Fig. 6. First, the outside diameter of the flange is determined by turning on a precision Hembrug lathe. The outside diameter of the flange is the same as that of the magnets in order to ensure good alignment of these components in the cylinder. Next, the outside diameter of the pressure divider is reduced over a certain length using a SARIX micro-electro discharge machine ( $\mu \mathrm{EDM}$ ). The main reason for this reduction in diameter is to deal with misalignments between the pressure divider and the reflux channel inlet that is made in the cylinder wall (see Fig. 5). In step three, four grooves are milled to connect the clearance seal to the reflux channel. The orifice of the clearance seal is fabricated by $\mu$ EDM drilling in step four. Finally, the pressure divider is removed from the base material by wire- $\mu$ EDM.

The micromagnets are fabricated by laser micromachining at the company Audemars. The spacer is made from a steel caliper pen. This magnetically conductive pen is cut to length using wire$\mu E D M$, and the central bore is fabricated by $\mu$ EDM drilling. The fabrication processes used for the piston and the cylinder have been described in a former publication on clearance seals [1]. The cylinder is made by milling and reaming a brass cylinder on a KERN MMP micromilling machine. The piston rod is also made out of brass in order to avoid the piston to be attracted by the magnets of the seal. The piston rod has an outside diameter of $0.3 \mathrm{~mm}$ and an internal bore of $0.12 \mathrm{~mm}$.

The most challenging aspect of the actuator fabrication is the assembly of all the components. It is important to note that all the components of the seal are glued to the cylinder, and therefore, leakage is only possible through the gap between the piston and the seal. This gluing is however particularly difficult because very small amounts of glue must be dispensed in a controlled way, relatively deep into the cylinder. For this purpose, a glue nozzle was developed (see Fig. 7). The nozzle has an outside diameter of $120 \mu \mathrm{m}$ and

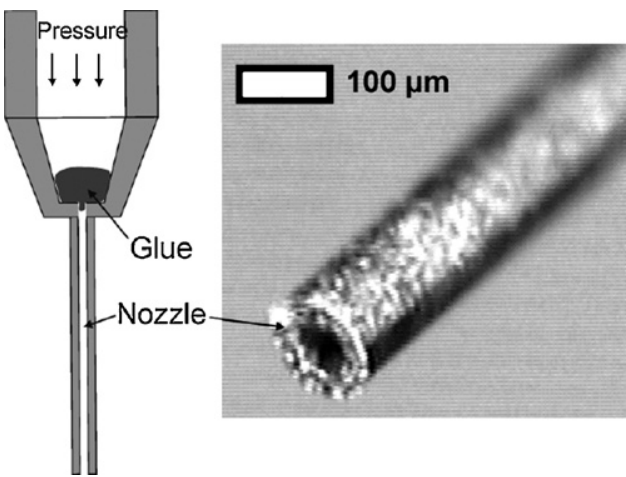

Fig. 7. Glue nozzle used for the assembly of the actuator.

an inside diameter of $60 \mu \mathrm{m}$. The nozzle is about $10 \mathrm{~mm}$ long and is used successfully with Loctite Hysol 9483 glue. Fig. 8 shows an actuator during the assembly process.

The actuator shown in Fig. 8 is using a plain clearance seal to isolate the two pressure chambers; alternatively, an actuator using an internal hybrid ferrofluid has been fabricated. This actuator is shown in Fig. 9, and is in accordance with the geometry presented in Fig. 5. In this case, the piston rod cannot be connected directly to the external system, since the reflux channel inside the piston rod must be connected to a tube. In order to overcome this problem, a clamping rod has been mounted on the piston as illustrated in Fig. 9.

Special attention is needed for the fluidic interconnections between the supply tubes and the cylinder wall. Glue based interconnections have been proposed in earlier publications [1,2]. Here, a modified version of the heat-shrink interconnections developed by Pan et al. [17] has been incorporated in the cylinder wall. These interconnections are fabricated in the following way (see Fig. 10): a channel with a flange is machined in the cylinder wall by $\mu$ EDM with Wire-Electro-Discharge-Grinding (WEDG) formed electrodes [18]. Next a micro-heat-shrink tube [19] is placed over the flange, which is then heated until the heat-shrink tube is enveloping it. Finally, an ordinary tube is connected to the other side of the heatshrink tube (see Figs. 8-10). Fig. 10a shows the connector before attaching the tube, Fig. 10b, after attaching the tube, and Fig. 10c shows a cross-section of the interconnection. The heat-shrink tube

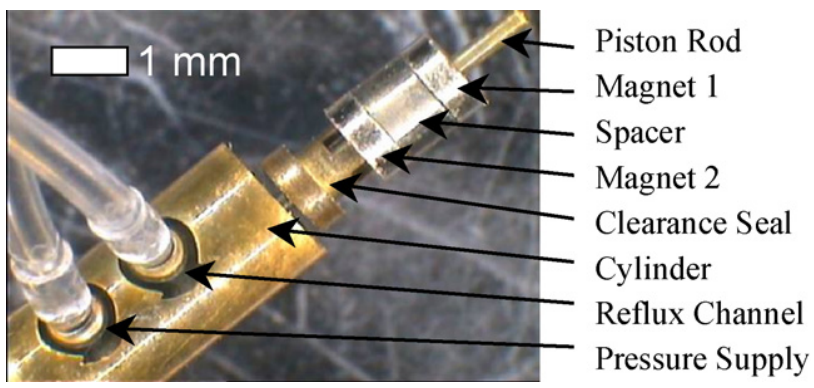

Fig. 8. Fluidic actuator with an external hybrid seal during assembly. 


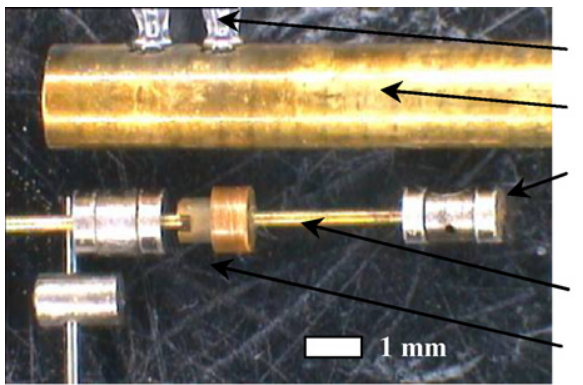

Pressure Supply

Cylinder

Internal Seal

Clamping rod

Piston rod

External Seal

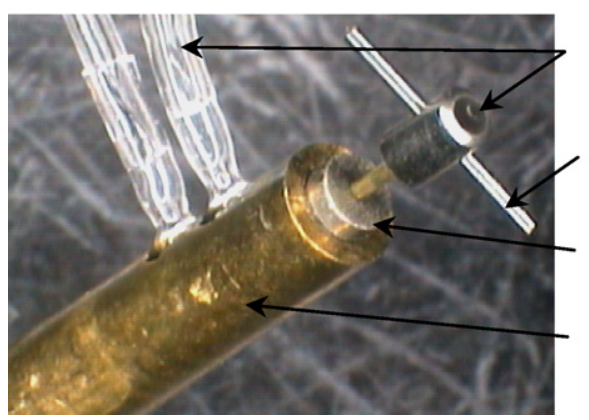

Reflux Channels

Clamping Rod

Magnet

Cylinder

Fig. 9. Fluidic actuator with an external and internal hybrid seal before (top) and after assembly (bottom).
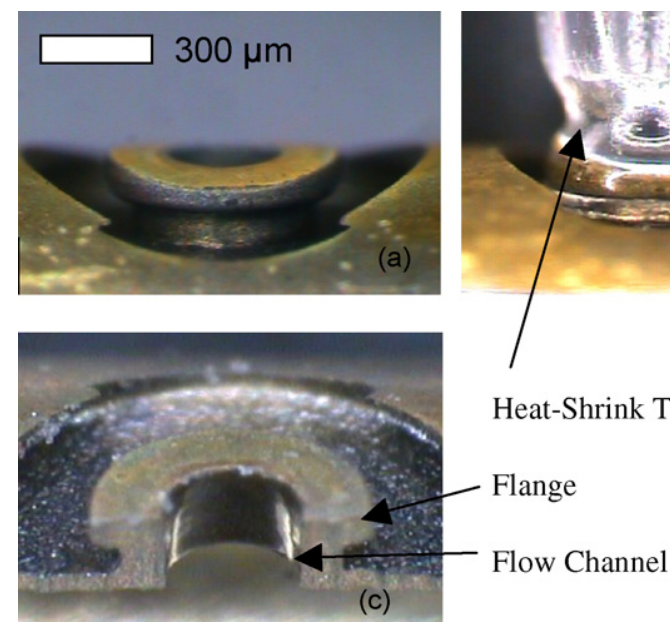

Fig. 10. Overview of the heat-shrink based fluidic interconnections implemented in this research. (a) Interconnection before attaching the tube, (b) interconnection after attaching the tube, and (c) cross-section of the fluidic interconnection.

used in this interconnection is the Iridium X2-025-CLR from the company Cobalt Polymers [19]. Measurements showed that these connections can resist normal forces of about $2 \mathrm{~N}$ and resist pressures of $1 \mathrm{MPa}$.

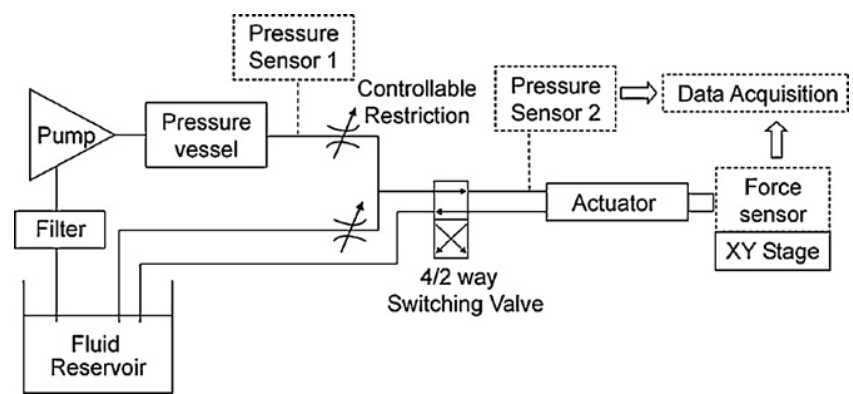

Fig. 11. Layout of the test setup used for the characterization of the fluidic microactuators.
Table 1

Measurement of the average seal pressure and its standard deviation.

\begin{tabular}{llllc}
\hline Fluid & Port 1 & Port 2 & Reflux & Seal pressure (kPa) \\
\hline Air or water & Closed & Pressurized & Closed & $130 \pm 40$ \\
Air & Open & Pressurized & Open & $260 \pm 50$ \\
Air & Pressurized & Open & Open & $500 \pm 40$ \\
Water & Open & Pressurized & Open & $540 \pm 50$ \\
Water & Pressurized & Open & Open & $>1600$ \\
\hline
\end{tabular}

\section{Measurements}

The actuators discussed above have been characterized in the test setup shown in Fig. 11. The hydraulic part of the setup consists of a membrane pump (Prominent $\gamma$ ) that can generate pressures up to $1.6 \mathrm{MPa}$ and two controllable restrictions that allow to adjust the pressure applied to the actuator. This pressure is measured by a MEMS based pressure sensor (Druck PMP 1400 ) while the actuation force is measured by a sensitive strain gauge bridge. Both variables are monitored by a data acquisition system. The system shown in Fig. 11 is used to drive the actuator with pressurized water. A similar setup is implemented to investigate the properties of the actuator when using pressurized air. All measurements are performed on the actuator shown in Fig. 8.

First, the maximum seal pressure of the actuator is determined for both pressurized air and water as driving fluid. The first row of Table 1 shows the maximum seal pressure when the pressure divider is switched off (reflux channel closed). In that case, the maximum seal pressure is $130 \mathrm{kPa}$, which is in good agreement
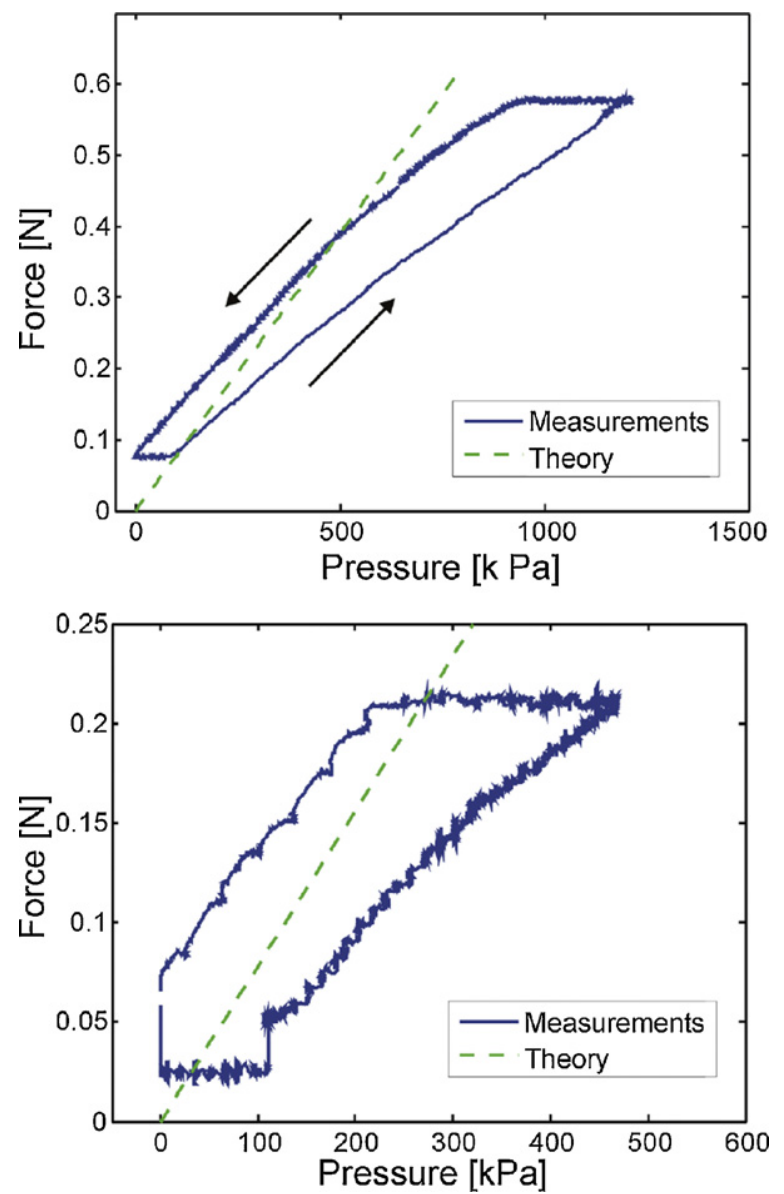

Fig. 12. Actuation force of the actuator as a function of the applied pressure in the case of pressurized water (top) and air (bottom). 

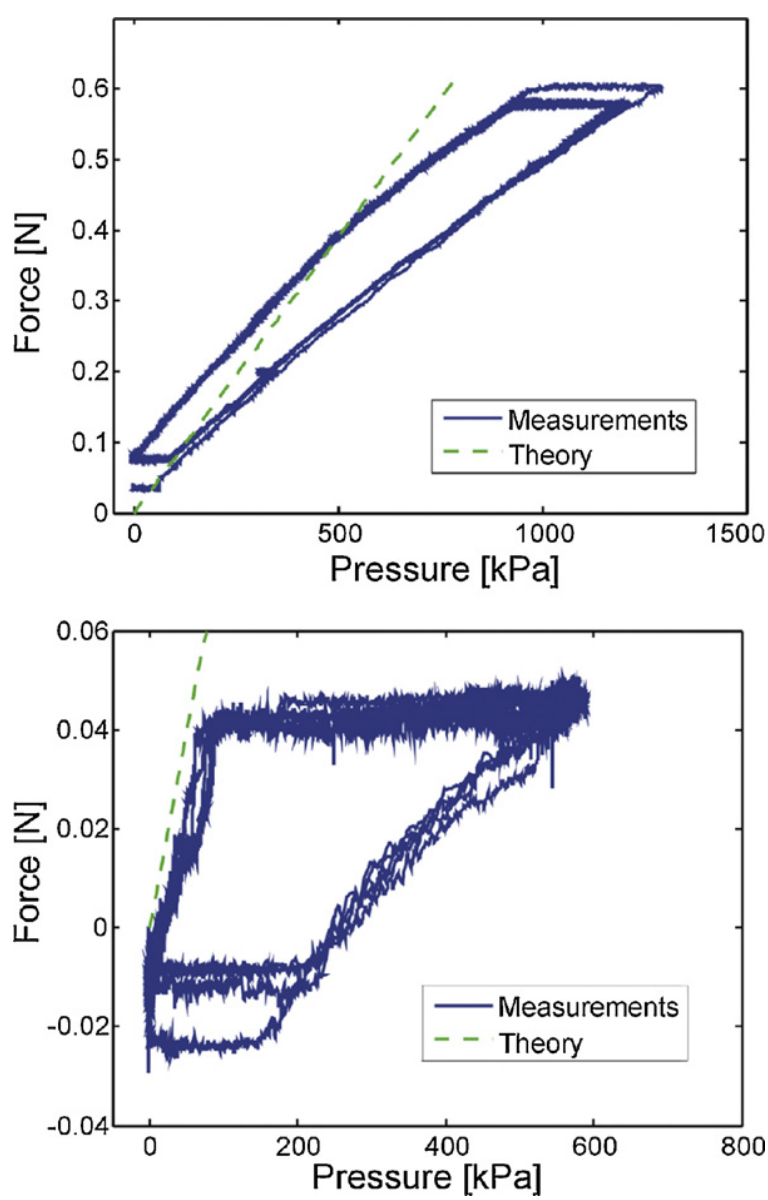

Fig. 13. Repeated actuation cycles for both the pushing force (top) and pulling force (bottom) of the actuator using pressurized water.

with the $112 \mathrm{kPa}$ estimated based on Eq. (1) earlier on. When using a pressure divider and water as driving fluid, the seal pressure is increased 4.2 times. This is in agreement with the factor 5 derived for $G$ earlier on. The maximum seal pressure is always higher if the pressure is applied on port 1 because in that case the piston acts as an additional seal. The relatively high standard deviation on the measurements shown in Table 1 is due to the fact that is sometimes difficult to detect the exact moment of failure of the seal. Also other factors that are difficult to control, such as the amount of ferrofluid in the seal and the eccentricity of the piston, influence the seal pressure [3].

Fig. 12 shows the actuation force of the actuator as a function of the applied pressure in the case of pressurized water (top) and air (bottom). These graphs also show the theoretical actuation force expected theoretically based on the applied pressure times the piston area. As can be seen in these figures, the actuator has a relatively high hysteresis. This hysteresis is not inherent to the seal technology, but is probably the result of friction between the piston and the cylinder due to misalignments in the assembly process. The hysteresis can be reduced slightly by using pressurized water instead of air as shown in Fig. 12. However, in order to reduce it significantly, the alignment of the piston needs to be improved. This is important in order to improve the linearity and controllability of the actuator [7]. Fig. 13 shows that the measured hysteresis is repeatable and that pulling force is lower than the pushing force, as expected from the smaller active piston area.

The flow through the reflux channel was $42 \mu \mathrm{l} / \mathrm{s}$ at a driving pressure of $200 \mathrm{kPa}$. This is in agreement with the 27-60 $\mu \mathrm{l} / \mathrm{s}$ estimated earlier on. The maximum actuation force measured was $0.65 \mathrm{~N}$ at
1.4 MPa. The actuation force is lower than the desired $1 \mathrm{~N}$ force but it can still be improved by increasing the driving pressure. However, the fluidic interconnections may need to be redesigned since leakage of the interconnections has been experienced at 1.6 MPa. The maximum seal pressure can also be increased by reducing the tolerances on the clearance seal.

The stroke of the actuator is $10 \mathrm{~mm}$, which is $77 \%$ of the actuator length. In addition, promising properties such as the restoration of the seal after a pressure overload have been observed. Finally, it should be noted that during these experiments the actuator is driven by large scale commercially available valves. Nevertheless, similar experiments could also be performed using for instance the microvalves presented in Ref. [20].

\section{Conclusions}

Hydraulic microactuators show promising properties for the generation of high force densities at microscale. However, appropriate microseals need to be developed in order to seal these actuators. This paper presents a new seal technology that combines a clearance seal with a ferrofluid seal. These seals are able to seal high pressures without leakage and with low friction. Therefore, they are particularly interesting for microapplications. These seals have been designed and integrated in a miniaturized fluidic actuator. Forces up to $0.65 \mathrm{~N}$ at a driving pressure of $1.4 \mathrm{MPa}$ have been observed. The actuation stroke is $77 \%$ of the total actuator length.

\section{Acknowledgements}

This research is sponsored by the Institute for the Promotion of Innovation by Science and Technology in Flanders (IWT) and by the Fund for Scientific Research - Flanders (FWO).

\section{References}

[1] M. De Volder, J. Peirs, D. Reynaerts, J. Coosemans, R. Puers, O. Smal, B. Raucent, Production and characterisation of a hydraulic microactuator, Journal of Micromechanics and Microengineering 15 (2005) S15-S21.

[2] M. De Volder, J. Peirs, D. Reynaerts, J. Coosemans, R. Puers, O. Smal, B. Raucent, A novel hydraulic microactuator sealed by surface tension, Sensors and Actuators A $123-124$ (2005) 547-554.

[3] M. De Volder, P. Goethals, S. Eeckhoudt, J. Peirs, D. Reynaerts, A ferrofluid seal technology for hydraulic microactuators, in: Proceedings of Actuator 2006 Conference, 2006, pp. 693-696.

[4] A.A. Norton, M.A. Minor, Pneumatic microactuator powered by the deflagration of sodium azide, Journal of Microelectromechanical Systems 15 (2006) 344-354.

[5] U. Gebhard, H. Hein, E Just, P. Ruther Combination of a fluidic micro-oscillator and micro-actuator in LIGA-technique for medical application, in: Proceedings of Tansducers97 Conference, 1997, pp. 761-764.

[6] M. De Volder, F. Ceyssens, D. Reynaerts, R. Puers, A PDMS lipseal for hydraulic and pneumatic microactuators, Journal of Micromechanics and Microengineering (2007) 1232-1237.

[7] M. De Volder, J. Coosemans, R. Puers, D. Reynaerts, Characterization and control of a pneumatic microactuator with an integrated inductive position sensor, Sensors and Actuators A 141 (2008) 192-200.

[8] Y.-C. Su, L. Lin, A water-powered osmotic microactuator, Journal of Microelectromechanical Systems 11 (2002) 736-742.

[9] K. Takemura, S. Yokota, K. Edamura, Development and control of a micro artificial muscle cell using electro-conjugate fluid, Sensors and actuators A 133 (2007) 493-499.

[10] R. Abe, K. Takemura, K. Edamura, S. Yokota, Concept of a micro finger using electro-conjugate fluid and fabrication of a large model prototype, Sensors and Actuators A 136 (2007) 629-637.

[11] R.E. Rosensweig, Ferrohydrodynamics, Cambridge University Press,1985

[12] Website of Ferrotec Corp., www.ferrotec.com.

[13] Z. Jibin, Z. Jiming, H. Jianhui, Design and pressure control of high-pressure differential magnetic fluid seals, IEEE Transactions on Magnetics 39 (2003) 2651-2653.

[14] K. Sekine, Y. Mitamura, S. Murabayashi, I. Nishimura, R. Yozu, D.W. Kim, Development of a Magnetic fluid shaft seal for an axial-flow blood pump, Artificial Organs 27 (2003) 892-896.

[15] Y.S. Kim, K. Nakatsuka, T. Fujita, T. Atarashi, Application of hydrophilic magnetic fluid to seal oil, Journal of Magnetism and Magnetic Materials 201 (1999) 361363. 
[16] M. De Volder, P.-J. Corthouts, I. Dogan, J. Peirs, D. Reynaerts, Microvalves driven by magnetorheologic fluids: opportunities and limitations, in: Proceedings of 16th Micromechanics Europe (MME) Workshop, 2005, pp. 378-381.

[17] T. Pan, A. Baldi, B. Ziaie, A reworkable adhesive-free interconnection technology for microfluidic systems, Journal of Microelectromechanical Systems 15 (2006) 267-272.

[18] X. Song, D. Reynaerts, W. Meeusen, H. Van Brussel, Investigation of micro-EDM for silicon microstructure fabrication, in: Proceedings of SPIE Symposium on Micromachining and Microfabrication, 1999, pp. 792-799.

[19] Website of Cobalt Polymers, www.cobaltpolymers.com.

[20] M. De Volder, K. Yoshida, S. Yokota, D. Reynaerts, The use of liquid crystals in microsystems: model and measurements, Journal of Micromechanics and Microengineering 16 (2006) 612-619.

\section{Biographies}

Michael De Volder was born in Antwerp, Belgium, in 1978. He received his maste degree in mechanical engineering from the University of Leuven (Belgium) in 2002.
He performed his $\mathrm{Ph} . \mathrm{D}$. research at the same university on hydraulic microactuators and microvalves. In 2005, he stayed as a visiting researcher at the Precision \& Intelligence Laboratory of the Tokyo Institute of Technology. In 2007, he obtained his Ph.D. degree and started his postdoctoral research in collaboration with IMEC, Belgium. In 2008, he stayed as a visiting postdoctoral researcher in nanotechnology at the Massachusetts Institute of Technology, and the University of Michigan. His current interests include micro- and nanotechnology.

Dominiek Reynaerts was born in Tienen, Belgium, in 1963. He received his mechanical engineering degree from the Katholieke Universiteit Leuven, Belgium, in 1986 He has been working at the Mechanical Engineering Department of that same university, as a research assistant, starting from 1986. He obtained his Ph.D. degree in mechanical engineering in 1995, and became assistant professor at the Katholieke Universiteit Leuven in 1997. He currently is a professor in mechanical engineering with research and teaching activities in precision engineering, micro-mechanical systems, advanced actuators and design methodology. He is a member of IEEE and euspen. 